Acknowledgments: The study was supported by a Discovery Grant from the National Psoriasis Foundation.

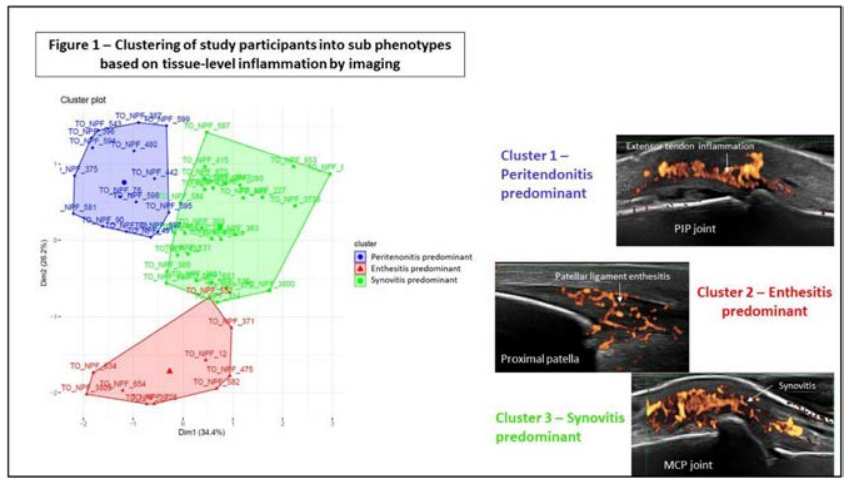

Disclosure of Interests: Lihi Eder Grant/research support from: Abbvie, Lily, Janssen, Amgen, Novartis, Consultant of: Janssen, Speakers bureau: Abbvie, Lily, Janssen, Amgen, Novartis, Quan Li: None declared, Sara Rahmati: None declared, Iris Eshed: None declared, Proton Rahman Grant/research support from: Janssen and Novartis, Consultant of: Abbott, AbbVie, Amgen, BMS, Celgene, Lilly, Janssen, Novartis, and Pfizer., Speakers bureau: Abbott, AbbVie, Amgen, BMS, Celgene, Lilly, Janssen, Novartis, Pfizer, Igor Jurisica Grant/ research support from: IBM, Vinod Chandran Grant/research support from: Abbvie, Celgene, Consultant of: Abbvie, Amgen, Bristol-Myers Squibb, Celgene, Eli Lily, Janssen, Novartis, Pfizer, UCB, Employee of: Spouse employed by Eli Lily

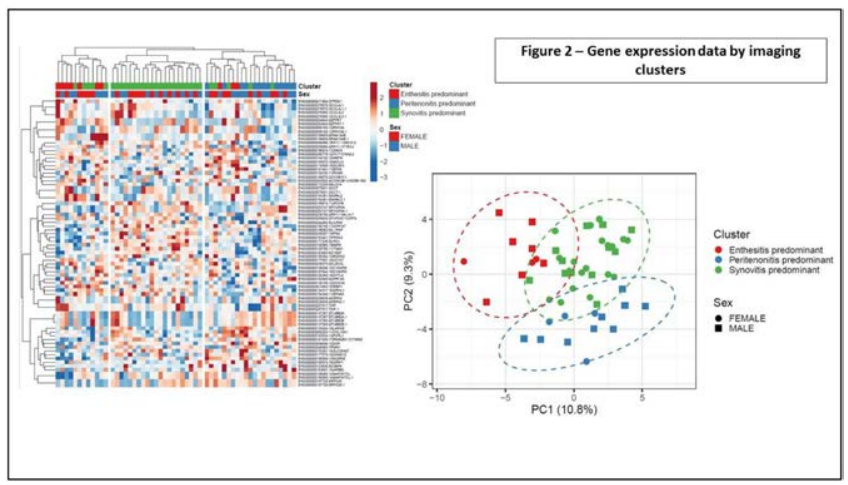

DOI: 10.1136/annrheumdis-2020-eular.1709

\section{SAT0360 \\ BACTERIAL TRANSLOCATION IN THE ADJUVANT INDUCED ARTHRITIS MODEL: PRELIMINARY STUDY AND IMPACT OF NSAIDS}

S. Hecquet ${ }^{1}$, R. Bordy ${ }^{2}$, C. Prati ${ }^{1}$, D. Wendling ${ }^{1}$, C. Demougeot ${ }^{2}$, F. Verhoeven ${ }^{1}$. ${ }^{1}$ CHRU Jean Minjoz, Rheumatology, Besançon, France; ${ }^{2}$ PEPITE EA4267, Besançon, France

Background: In patients with spondyloarthritis, the presence of intestinal inflammation and an increase in digestive permeability responsible for bacterial translocation has been described. No data are available on the effect of non-steroidal anti-inflammatory drugs (NSAIDs) on this bacterial translocation in patients with spondyloarthritis. Zonulin and lipopolysaccharide (LPS) have been described as good biomarkers of intestinal permeability and bacterial translocation, respectively. Adjuvant-induced arthritis (AIA) is a model of recent arthritis characterized by ossification and ankylosis in the post arthritis period. This model can be considered as a model of reactive arthritis in which our previous work has reported a clear efficacy of NSAIDs with differences between molecules at the structural and vascular levels.

Objectives: To test the hypothesis that there is an increase in digestive permeability and bacterial translocation in the AIA model and to show the influence of different NSAIDs on these two parameters.

Methods: Adjuvant-induced arthritis (AIA) was induced in 6-week-old male Lewis rats by an injection at the base of the tail of Mycobacterium butyricum. A group of non-AIA (control) rats received saline. At the first signs of arthritis, the AIA-rats were evaluated (arthritis score 0-6) and treated daily intraperitoneally with naproxen $(10 \mathrm{mg} / \mathrm{kg} /$ day $)$, diclofenac $(5 \mathrm{mg} / \mathrm{kg}$ twice daily), celecoxib (3 mg/kg/day) or saline solution (AIA-vehicle group). After 21 days of treatment, the rats were sacrificed and serum levels of zonulin and LPS were

evaluated by ELISA and liquid chromatography-mass spectrometry, respectively. Circulating levels of TNF- $\alpha$ and IL1- $\beta$ and paw radiographic score were measured.

Results: Compared to the control group, there was a significant increase in zonulin concentration $(p<0.001)$ in the AIA group. There was no significant difference in the concentration of LPS between the two groups. The levels of zonulin were correlated with the TNF- $a$ levels $(R=-0.42 ; p=0.032)$ and the arthritis score $(R=0.45 ; p=0.013)$ but not with the level of IL1- $\beta(R=; p-0.018 ; p=0.39)$. Treatment with NSAIDs significantly and equivalently decreased the arthritis score in each group. Compared to the vehicle group, treatment with naproxen significantly decreased the radiographic score $(p<0.001)$, TNF- $a$, IL1- $\beta(p<0.01)$, zonulin $(p<0.001)$ and LPS $(p<0.05)$. Celecoxib decreased radiographic score $(p<0.001)$, IL1- $\beta$ ( $p<0.01)$, TNF- $a(p<0.01)$ but increased zonulin levels $(p<$ 0.05 ) without effect on LPS. Diclofenac also decreased radiographic score ( $p<$ $0.001)$, TNF- $\alpha(p<0.01)$, and IL1- $\beta(p<0.01)$ but increased both zonulin ( $p<$ $0.01)$ and LPS $(p<0.001)$.

Conclusion: We have demonstrated an increase in serum zonulin levels in the AIA model and a beneficial effect of naproxen on intestinal permeability and bacterial translocation in contrast to celecoxib and diclofenac. Moreover, the plasmatic zonulin levels were correlated with TNF-a supporting a pivotal role of TNF-a on the tight junctions in this model.

Disclosure of Interests: Sophie Hecquet: None declared, Romain Bordy: None declared, Clément Prati: None declared, Daniel Wendling: None declared, Céline Demougeot Grant/research support from: With an institutional support from Pfizer., Frank Verhoeven: None declared DOI: 10.1136/annrheumdis-2020-eular.3508

\title{
SAT0361 HEALTHY HUMAN SPINAL PROCESSES PERI- ENTHESEAL T-CELLS EXHIBIT A TR1 RATHER THAN A FOXP3 REGULATORY PHENOTYPE
}

H. Rowe ${ }^{1}$, A. Watad ${ }^{1}$, T. Russell ${ }^{1}$, K. Sharif ${ }^{1}$, D. Newton ${ }^{1}$, M. Wittmann ${ }^{1}$, Q. Zhou ${ }^{1}$, A. Khan ${ }^{2}$, P. Loughenbury ${ }^{2}$, R. Dunsmuir ${ }^{2}$, A. S. Rao ${ }^{2}$, P. Millner ${ }^{2}$, T. Kenna ${ }^{3}$, M. Brown ${ }^{4}$, C. Bridgewood ${ }^{1}$, D. Mcgonagle ${ }^{1} .{ }^{1}$ University of Leeds, Leeds Institute of Rheumatic and Musculoskeletal Medicine, Leeds, United Kingdom; ${ }^{2}$ The Leeds Teaching Hospital, NHS Trust, Leeds, United Kingdom; ${ }^{3}$ Institute of Health and Biomedical Innovation, Queensland University of Technology, Woolloongabba, Australia; ${ }^{4}$ King's College London, London, United Kingdom

Background: We have previously reported that the normal spinal enthesis has populations of conventional T-cells including CD4+ \& CD8+ T-cells that could be induced to produce IL-17A and TNF following anti-CD3/CD28 stimulation. The biology of such cells in health including their normal function and antigen reactivity is completely unknown. The purpose of this work was to define the phenotype, functionality and TCR reactivity of such T-cells in health.

Figure 1. Transcriptional profiling of T-cells

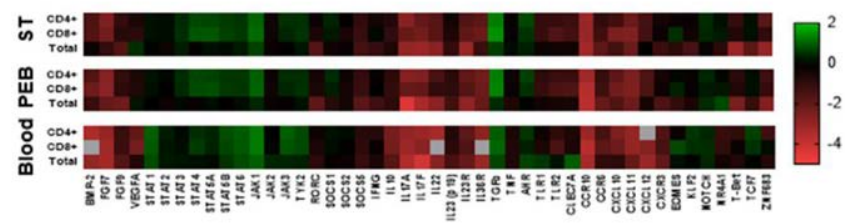

Figure 2. TGF $\beta$ from secretion enthesis T-cells

Stained

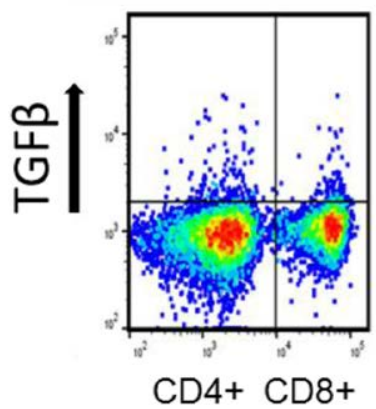

FMO

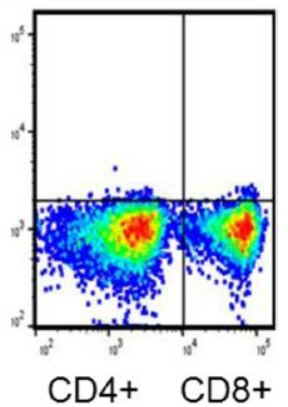


Objectives: To investigate whether the T-cells at the normal enthesis were regulatory in nature and to determine the type of regulatory T-cell as Tr1 or FOXP3 regulatory T-cell and to determine T-cell reactivity.

Methods: Healthy interspinous ligament and spinous process with matched peripheral blood were harvested from patients undergoing elective spinal surgery $(n=20)$. Entheseal soft tissue (EST) \& peri-entheseal bone (PEB) was enzymatically digested and then sorted. Tr1 and Treg phenotypes were investigated using flow cytometry. Analysis of cytokines, growth factors and chemokines was performed by qRT-PCR, ELISA and flow cytometry. TCR sequencing was performed and a search for putative T-cell reactivity was done using TCR3 database.

Results: Pro-inflammatory cytokine transcripts including IL-17A, IL-17F, IL-22, IL-23 (p19) \& TNF were very low or undetectable in the Enthesis T-cells (Fig 1). Flow cytometry confirmed entheseal T-cells had a Tr1 phenotype (CD4+ LAG3+ $\mathrm{CD} 49 \mathrm{~b}+$ ). Intracellular flow cytometry showed enthesis T-cells had very low FOXP3 expression, when compared to their blood counterparts. Intracellular flow cytometry and gene expression showed high basal expression of growth factors and regulatory proteins such as IL-10 \& TGF $\beta$, when compared to blood T-cells. RNA-Seq data, showed 13 potential TCR clonal sequences the most common of which are predicted to be reactive viral infection was CMV present in 8 sequences and Influenza A virus present in 2 sequences.

Conclusion: The healthy human enthesis has regulatory T-cells of a Tr1 phenotype rather than a FOXP3 Treg phenotype. Many clones have antigen specificity indicating reactivity to prior infection. These findings suggest that conventional entheseal T-cells have a role in enthesis immune homeostasis.

Disclosure of Interests: Hannah Rowe Grant/research support from: Novartis UK Investigator Initiated non-clinical research funding support, Abdulla Watad: None declared, Tobias Russell Grant/research support from: Novartis UK Investigator Initiated non-clinical research funding support, Kassem Sharif: None declared, Darren Newton: None declared, Miriam Wittmann: None declared, Qiao Zhou Grant/research support from: Funded by the PARTNER fellowship program, Almas Khan: None declared, Peter Loughenbury: None declared, Robert Dunsmuir: None declared, Abhay S Rao: None declared, Peter Millner: None declared, Tony Kenna: None declared, Matthew Brown: None declared, Charlie Bridgewood: None declared, Dennis McGonagle Grant/research support from: Janssen Research \& Development, LLC

DOI: 10.1136/annrheumdis-2020-eular.6689

\section{SAT0362 ASSOCIATION OF GUT DYSBIOSIS WITH STRUCTURAL DAMAGE AND ACTIVITY IN AXIAL SPONDYLOARTHRITIS PATIENTS. DATA FROM THE COSPAR REGISTRY.}

G. G. Ignacio ${ }^{1,2,3}$, I. Moreno-Indias s, $^{4,}$, M. D. C. Castro Villegas ${ }^{1,2,3}$, M. D. C. Abalos-Aguilera ${ }^{2,3}$, M. Ladehesa Pineda ${ }^{1,2,3}$, I. C. Aranda-Valera ${ }^{1,2,3}$, C. Gutierrez Repiso $0^{4,5}$, A. Escudero Contreras ${ }^{1,2,3}$, J. G. Yolanda ${ }^{6,7}$, N. Barbarroja ${ }^{2,3}$, F. J. Tinahones ${ }^{4,5}$, E. Collantes Estevez ${ }^{1,2,3}$, P. RuizLimon ${ }^{4} .{ }^{1}$ Hospital Reina Sofía, Córdoba, Spain; ${ }^{2}$ Instituto Maimónides de Investigación Biomédica de Córdoba, Córdoba, Spain; ${ }^{3}$ University of Cordoba, Córdoba, Spain; ${ }^{4}$ Unidad de Gestión Clínica de Endocrinología y Nutrición, IBIMA, Hospital Clínico Virgen de la Victoria, Málaga, Spain; ${ }^{5}$ CIBEROBN, Instituto de Salud Carlos III, Málaga, Spain; ${ }^{6}$ Instituto Maimónides Investigación Biomédica de Córdoba, Córdoba, Spain; ${ }^{7}$ University of Córdoba, Córdoba, Spain

Background: The etiopathogenesis of axial spondyloarthritis (AxSpA) is multifactorial. The possible role of alteration in gut microbiome (dysbiosis) has been recently suggested. However, the association of dysbiosis with structural damage is still unknown and further studies are needed to assess its association with disease activity.

Objectives: To determine the alterations in the gut microbiota in AxSpA patients To evaluate whether changes in the gut microbiota in AxSpA patients are associated with structural damage or disease activity.

Methods: Fifteen AxSpA patients and 15 healthy donors (HDs) were included in a cross-sectional study. Disease activity variables such as $\mathrm{C}$-reactive protein and ESR were measured. Structural damage was determined by lateral $\mathrm{X}$-rays of the cervical and lumbar spine to establish the mSASSS index. Axial mobility was evaluated using the BASMI index and the enthesis affectation was evaluated using ultrasound to obtain the MASEI index. Gut microbiota was measured using the lon Torrent S5 platform and sequences were processed using the QIIME2. Chi-square and Mann-Whitney U were used, and correlations were determined using the Spearman Rho test. Significant differences were considered $p<0.05$

Results: Alpha diversity indicators, such as the number of observed OTUs group and the faith index, showed a greater richness in AxSpA compared to HDs $(p=0.03$ and $p=0.01)$. A significant decrease in family Bacteroidaceae $(p=0.006)$ and an increase in families Synergistaceae and Bifidobacteriaceae were found in the microbiota of $\mathrm{AxSpA}(\mathrm{p}=0.036, p=0.049)$. According to genera, Bacteroides decreased in AxSpA ( $p=0.006)$, while Dialister and Bifidobacterium increased $(p=0.010$ and $p=0.046)$. Positive correlation among lumbar mSASSS $(r=0.508$ $\mathrm{p}=0.019$ ) and Synergistaceae was found. This family was also increased along with the increase in enthesis damage (MASEl index $(r=0.656, p=0.028)$ ) and axial mobility by the BASMI index $(r=0.529, p=0.011)$. Correlation studies between the decrease in Bacteroidaceae and Bacteroides with disease activity measured by ASDAS ( $r=-0.697, p=0.025 ; r=-0.770, p=0.009)$ was also significant. Positive cor relation was observed between Dialister with mSASSS $(r=0.549, p=0.010)$ and BASMI $(r=0.512, p=0.015)$.

Conclusion: 1) AxSpA patients had a significant alteration of the gut microbiota. 2) These alterations are associated with radiographic damage, disease activity, affectation of enthesis and axial mobility.

Acknowledgments: PRL, supported by "Sara Borrell" (CD19/00216), IMI supported by "Miguel Servet tipo I" (CP16/00163), CGR supported by JdC Incorporación (IJCl-2017-33065). This work is supported by JA PI-0151-2018. Pablo Rodríguez Bada metagenomic platform CIBER-IBIMA.

Disclosure of Interests: Gómez García Ignacio: None declared, Isabe Moreno-Indias: None declared, María del Carmen Castro Villegas: None declared, Maria del Carmen Abalos-Aguilera: None declared, MLourdes Ladehesa Pineda: None declared, Inmaculada Concepcion Aranda-Valera: None declared, Carolina Gutierrez Repiso: None declared, Alejandro Escudero Contreras Grant/research support from: ROCHE and Pfizer, Speakers bureau: ROCHE, Lilly, Bristol and Celgene., Jiménez Gómez Yolanda: None declared, Nuria Barbarroja: None declared, Francisco Jose Tinahones: None declared, Eduardo Collantes Estevez Grant/research support from: ROCHE and Pfizer, Speakers bureau: ROCHE, Lilly, Bristol and Celgene, Patricia Ruiz-Limon: None declared

DOI: 10.1136/annrheumdis-2020-eular.6364

\section{\begin{tabular}{|l|l}
\hline SAT0363 DELPHINIDIN DOSE-DEPENDENTLY DIMINISHES \\
\hline
\end{tabular} PERIPHERAL IL-17 AND IFN-Г PRODUCING LYMPHOCYTES IN PSORIATIC ARTHRITIS}

A. Mavropoulos ${ }^{1}$, S. Tsiogkas ${ }^{1}$, D. Skyvalidas ${ }^{1}$, C. Liaskos ${ }^{1}$, A. RoussakiSchulze $^{2}$, E. Zafiriou ${ }^{2}$, D. Bogdanos ${ }^{1}$, L. Sakkas ${ }^{1} .{ }^{1}$ University of Thessaly, Rheumatology and clinical immunology, Faculty of Medicine, Larissa, Greece; ${ }^{2}$ University of Thessaly, Dermatology, Faculty of Medicine, Larissa, Greece

Background: Delphinidin, a dietary anthocyanidin and powerful anti-oxidant from pigmented fruits and vegetables, has broad anti-inflammatory properties. In a human skin model of psoriasis, delphinidin reduced expression of proliferative and inflammatory markers (1).

Objectives: The rationale of our study was to assess whether delphinidin can in vitro suppress IL-17 and IFN- $\gamma$ production in peripheral blood mononuclear cell (PBMC) subsets from patients with psoriatic arthritis (PsA).

Methods: PBMCs were obtained from 24 patients with PsA attending the outpatient clinic of the Department of Rheumatology/clinical Immunology at the University General Hospital of Larissa, Greece. 16 age- and sex-matched healthy volunteers were also included in the study. Delphinidin was supplemented at a concentration ranging from 1 to $50 \mu \mathrm{g} / \mathrm{ml}$, one hour prior to cell stimulation. Cell viability (Annexin V staining) and innate/adaptive lymphocyte subpopulations were assessed by flow cytometry with a panel of fluorochrome-conjugated antibodies against CD56, CD3, CD4 and CD8. Intracellular expression of IL-17 and IFN- $\gamma$ was measured following PMA/ionomycin stimulation for 5 hours using standard cell permeabilization protocols and monoclonal antibodies against IL-17 and IFN- $\gamma$

Results: Delphinidin at concentration $\geq 10 \mu \mathrm{g} / \mathrm{ml}$ sharply diminished IL-17-production by CD4(+) T cells (Th17) and CD56(+)CD3(+) (NKT) cells from patients with psoriatic arthritis and normal controls $(p \leq 0.05)$. IFN- $\gamma$ producing $T$ (CD4 and CD8) cells, as well as NK and NKT cells were also dose-dependently suppressed following delphinidin pre-incubation in both patients and healthy controls. Inhibition of IFN- $\gamma(+)$ cells ranged from 27 to $69 \%$ and peaked at delphinidin concentration $20-50 \mu \mathrm{g} / \mathrm{ml}$. The inhibitory effect of delphinidin on IL-17 and IFN- $\gamma$ producing lymphocytes was not due to compromised cell viability, as assessed by annexin $\mathrm{V}$ binding.

Conclusion: Delphinidin exerts, in a dose-dependent manner, a profound in vitro inhibitory effect on T cell and NKT cell IL-17 and IFN- $\gamma$ production in PSA, and therefore, it may be used as a dietary immunosuppressant, complementary to standard treatment.

\section{References:}

[1] Chamcheu JC Skin Pharmacol Physiol. 2015;28(4):177-88. doi: 10.1159/000368445

Disclosure of Interests: ATHANASIOS MAVROPOULOS: None declared, Sotirios Tsiogkas: None declared, Dimitrios Skyvalidas: None declared, Christos Liaskos: None declared, Aggeliki Roussaki-Schulze Grant/research support from: Received a grant to support the educational and research activities of the 